\title{
Beneficial Effects of Trehalose on Striatal Dopaminergic Deficits in Rodent and Primate Models of Synucleinopathy in Parkinson's Disease
}

\author{
Patrick A. Howson, Tom H. Johnston, Paula Ravenscroft, Michael P. Hill, Jin Su, \\ Jonathan M. Brotchie, and James B. Koprich
}

Atuka Inc., Toronto, Ontario, Canada (T.H.J., P.R., M.P.H., J.S., J.M.B., J.B.K.); Junaxo Inc., Toronto, Ontario, Canada (P.A.H.); and Krembil Research Institute, University Health Network, Toronto, Ontario, Canada (P.A.H., T.H.J., P.R., M.P.H., J.M.B., J.B.K.)

Received December 6, 2018; accepted March 18, 2019

\begin{abstract}
Disease modification in Parkinson's disease (PD) is an unmet medical need. In the current study, we evaluated trehalose, a safe and well-tolerated disaccharide that has previously demonstrated efficacy in rodent models of neurodegenerative diseases, including PD. In a rat model of PD, based on delivery of adeno-associated virus serotype $1 / 2$ containing the mutated human A53T $\alpha$-synuclein gene (AAV1/2-hourA53T-aSyn) to the substantia nigra $(\mathrm{SN})$, we showed that rats administered trehalose $(2.67 \mathrm{~g} / \mathrm{kg}$ per day, by mouth) for 6 weeks had less forelimb asymmetry (93\% reduction) and higher striatal dopamine (54\% increase) compared with rats receiving vehicle. In a pharmacokinetic study, we determined that efficacy was associated with plasma $C_{\max }$ of $8900 \mathrm{ng} / \mathrm{ml}$ and area under the curve from time 0 to infinity $\left(\mathrm{AUC}_{0-\text { inf }}\right)$ of $11,136 \mathrm{hour} \cdot \mathrm{ng} / \mathrm{ml}$. We then showed, in macaques, that oral administration of
\end{abstract}

trehalose $(2.67 \mathrm{~g} / \mathrm{kg}$ per day) produced plasma exposures of similar magnitude, with plasma $C_{\max }$ of $10,918 \mathrm{ng} / \mathrm{ml}$ and $\mathrm{AUC}_{0-\text { inf }}$ of 27,445 hour.ng/ml. In a macaque model of PD, also based on delivery of AAV1/2-hourA53T-aSyn to the SN, trehalose $(2.67 \mathrm{~g} / \mathrm{kg}$ per day, by mouth), administered for 142 days, produced higher striatal dopamine (by 39\%) and dopamine transporter levels (by 50\%), compared with macaques receiving vehicle. In neither model did trehalose treatment prevent loss of tyrosine hydroxylase (TH) positive $\left(\mathrm{TH}^{+\mathrm{ve}}\right)$ cells in the $\mathrm{SN}$ or alter $\alpha$-synuclein levels in the striatum. These studies demonstrated that trehalose reduces striatal dopaminergic deficits in a rodent and macaque model of synucleinopathy in PD. Furthermore, we have determined the pharmacokinetic parameters associated with efficacy, and thus defined exposures to target in future clinical trials.

\section{Introduction}

Parkinson's disease (PD) is a progressive neurodegenerative disorder characterized, but not exclusively, by loss of dopaminergic neurons and the presence of Lewy bodies in remaining neurons of the substantia nigra (SN) (Dawson and Dawson, 2003; Siderowf and Stern, 2003). Lewy bodies are predominantly composed of abnormal misfolded $\alpha$-synuclein (aSyn) (Iwatsubo, 2003; Cole et al., 2005), and increased levels of aSyn mRNA are found in the midbrain of patients with sporadic PD (Chiba-Falek et al., 2006). Furthermore, duplication or triplication of the aSyn gene (Polymeropoulos et al., 1997), and missense mutations in the aSyn gene including A53T, A30P, and E46K (Polymeropoulos et al., 1997; Krüger et al., 1998; Zarranz et al., 2004), are known to cause PD.

The Michael J. Fox Foundation had no role in the study design, data collection and analysis, decision to publish, and preparation of the manuscript. This work was supported by the Michael J. Fox Foundation.

https://doi.org/10.1124/jpet.118.255695.
These findings suggest that abnormal aSyn expression contributes to Lewy body formation in PD brains (Singleton et al., 2003; Song et al., 2009), and thus assessing therapeutic interventions intended to slow disease progression in animal models based on overexpression of aSyn is an important step in developing drugs to treat PD.

Trehalose, a disaccharide formed by an $\alpha, \alpha$-1,1-glucoside bond between two $\alpha$-glucose molecules is beneficial in various animal models of neurodegeneration (for a recent review, see Hosseinpour-Moghaddam et al., 2018). In animal models of $\mathrm{PD}$, trehalose has demonstrated efficacy in toxin-induced lesion models (Sarkar et al., 2014; Ferguson et al., 2015; Wu et al., 2015), in models overexpressing mutant aSyn by viral vectors (He et al., 2016), and by transgenesis (Tanji et al., 2015).

The neuroprotective mechanism of trehalose in animal models of PD is not well understood. Several studies have proposed that trehalose is an autophagy enhancer (Sarkar et al., 2007; Casarejos et al., 2011; Lan et al., 2012; Zhao et al., 2017) but have failed to delineate how trehalose enhances

ABBREVIATIONS: AAV1/2, adeno-associated virus serotype 1/2; AAV1/2-hourA53T-aSyn, adeno-associated virus serotype 1/2 containing the mutated human A53T $\alpha$-synuclein gene; aSyn, $\alpha$-synuclein; AUC $_{0-\text { inf, }}$, area under the curve from time 0 to infinity; CSF, cerebrospinal fluid; DAT, striatal dopamine transporter; DOPAC, dihydroxyphenylacetic acid; EV, empty vector; HPLC, high-performance liquid chromatography; HVA, homovanillic acid; LC-MS/MS, liquid chromatography-tandem mass spectrometry; MPTP, 1-methyl-4-phenyl-1,2,3,6-tetrahydropyridine; NHP, nonhuman primate; PD, Parkinson's disease; $S N$, substantia nigra; $t_{1 / 2}$, half-life; $\mathrm{TH}$, tyrosine hydroxylase. 
autophagy. Contrarily, it has also been reported that trehalose inhibits autophagic flux (Yoon et al., 2017). Even if trehalose is an autophagy enhancer it is difficult to explain how trehalose could produce neuroprotection in a toxin-lesioned model of PD, such as 1-methyl-4-phenyl-1,2,3,6-tetrahydropyridine (MPTP) (Sarkar et al., 2014), without additional actions.

Several other effects of trehalose, independent of autophagy, have also been suggested to confer the neuroprotective effects of trehalose, including being a chemical chaperone (Crowe, 2007; Sarkar et al., 2014), downregulation of poly(ADP-ribose) polymerase (Spina-Purrello et al., 2010), regulation of stress granules (Dimasi et al., 2017), anti-inflammatory actions (Echigo et al., 2012; Pagliassotti et al., 2017; Mirzaie et al., 2018), inducer of neurotrophic factors (Perucho et al., 2016; Portbury et al., 2017a,b), and reduction of oxidative stress (Gao et al., 2018; Mizunoe et al., 2018). Any one of these mechanisms, or more likely a combination of several of these mechanisms, may be responsible for the neuroprotective effects of trehalose. Irrespective of the mechanism, that it does provide neuroprotection has been empirically demonstrated multiple times in a variety of experimental models showing that trehalose can provide a broad, neuroprotective effect.

In all of the PD preclinical studies that have evaluated trehalose in vivo, it has been administered ad libitum in drinking water; therefore, it remains unknown whether trehalose would be beneficial if it was administered in a way more amenable to be developed as a therapeutic, e.g., as a single, daily oral administration. In addition, none of these prior studies investigated the pharmacokinetics of trehalose associated with the efficacious effects, thus exposures to target in clinical studies are unknown. Finally, to date, trehalose has only been evaluated in rodent models of PD; therefore, whether the effects of trehalose translate to nonhuman primates (NHPs) remains unknown. Demonstrating efficacy in NHPs is an important step in translating to clinical trials, since it demonstrates efficacy in a species with a more humanrelated anatomic organization. For example, in contrast to rodents, the brains of some primate species (including humans, rhesus macaques, and cynomolgus macaques) contain melanized neurons. In addition, evaluation in multiple species, with appropriate pharmacokinetic analysis, helps define dosing regimens for use in clinical studies.

These knowledge gaps mean it is not clear how trehalose should be developed as a therapeutic for treating PD. The present studies were designed: 1) to evaluate in a rodent model of PD different dosing regimens providing the same total daily dose of trehalose; 2 ) to determine in the rodent the plasma and brain pharmacokinetics of trehalose associated with efficacy; 3) to define how to achieve those exposures in NHPs; and 4) to evaluate whether trehalose, administered to achieve target exposures, was efficacious in a macaque, aSyn-driven model of PD pathology.

\section{Materials and Methods}

\section{Chemicals and Reagents}

Trehalose was purchased from Atuka Inc., and was 98\% pure. All other reagents used were of analytical grade. The gene for human A53T $\alpha$-synuclein (hA53T-aSyn, accession number P37840, variant ID VAR_007454) was inserted into a chimeric adeno-associated virus [adeno-associated virus serotype 1/2 (AAV1/2)] as previously described
(Koprich et al., 2010). As a control, the same chimeric vector, but without any gene inserted, was used [AAV1/2-empty vector (EV)]. All of the vectors were ordered from GeneDetect Ltd. (Auckland, New Zealand).

\section{Animal Husbandry and Ethical Statement}

For the rodent studies, normal specific pathogen-free female Sprague-Dawley rats (Charles River), 250-275 g on delivery were acclimatized for 1 week. Rats were housed two per cage at standard temperature $\left(21 \pm 2^{\circ} \mathrm{C}\right)$ in a light-controlled environment (lights on 7 : $00 \mathrm{AM}$ to 7:00 PM) with access to food (Teklad 7912; Harlan, Madison, WI) and water ad libitum. The studies were conducted under an institution approved animal use permit according to guidelines set by the Canadian Council on Animal Care (https://www.ccac.ca/en/ standards/guidelines/).

For the macaque studies, normal previously untreated specific pathogen-free female cynomolgus macaques (Macaca fascicularis, 8.0-9.3 years, 3.2-4.4 kg, Suzhou-Xishan-Zhongke Company, People's Republic of China) were acclimatized to the experimental setting for at least 3 months prior to use. Animals were group housed with cage sizes exceeding European, United Kingdom, European Union, National Institutes of Health, and Canadian Councils on Animal Care minimum recommendations. Cages were enriched with environmental stimuli including perch, foraging boards, and toys. The housing room was subject to a 12-hour lightdark cycle (lights on $7 \mathrm{AM}$ ) at temperatures of $21-26^{\circ} \mathrm{C}$. Fresh fruit, primate pellets, and water were available ad libitum except from $11 \mathrm{AM}$ on day of behavioral observations and blood sampling. All studies were performed in an Association for Assessment and Accreditation of Laboratory Animal Care accredited facility at Suzhou Xishan Zhongke Drug R\&D Co, Ltd. (Jiangsu, People's Republic of China) with local Institutional Animal Care and Use Committee approval and in accordance with the Guide for the Care and Use of Laboratory Animals as adopted by the National Institutes of Health Institute of Laboratory Animal Resources Committee on Care and Use of Laboratory Animals (1996) (https:// grants.nih.gov/grants/olaw/guide-for-the-care-and-use-of-laboratory-animals.pdf).

\section{Liquid Chromatography-Tandem Mass Spectrometry}

Quantitative analysis of trehalose in rat and macaque plasma and brain tissue was performed on a liquid chromatography-tandem mass spectrometry (LC-MS/MS) system. All LC-MS/MS analyses were performed on a Shimadzu LC-10AD pump equipped with a CTCHTS Autosampler (Zwingen, Switzerland) and a column oven (Tianjin, China). The tandem mass spectrometry system was an MDS Sciex API-4000 mass spectrometer with an electrospray ionization probe (Toronto, Canada).

Chromatographic separations of the analytes were achieved on a Phenomenex Luna hydrophilic interaction liquid chromatography column $(100 \times 2 \mathrm{~mm}, 3.0 \mu \mathrm{m})$. The total run time was 4.0 minutes and the elution of trehalose and internal standard (sucrose) occurred at 2.88 and 2.55 minutes, respectively. The mobile phase consisted of two phases; phase A was $\mathrm{H}_{2} \mathrm{O}$ and phase $\mathrm{B}$ was acetonitrile. Over the 4-minute run time, the percentages of phase $\mathrm{B}$ in the mobile phase were 90\% (0-0.5 minutes), 75\% (0.5-2.0 minutes), and 90\% (2-4 minutes). The flow rate was constant $(0.5 \mathrm{ml} / \mathrm{min})$ and the experiment was performed at ambient temperature. Analytes were detected by multiple reactions monitoring and in negative ion mode. The optimal transitions were mass-to-charge ratio $341.2 \rightarrow 89$ for trehalose and mass-to-charge ratio $341.2 \rightarrow 89$ for sucrose. The key mass spectrometry parameters were: curtain gas (20 psi), gas 1 (45 psi), gas $2(40 \mathrm{psi})$, ion spray voltage $(-4000 \mathrm{~V})$, temperature $\left(350^{\circ} \mathrm{C}\right)$, declustering potential $(-79 \mathrm{~V})$, collisionally activated dissociation $(4 \mathrm{~V})$, collision energy $(-28 \mathrm{eV})$, and collision cell exit potential $(-15 \mathrm{~V})$. 


\section{Rodent Studies}

Efficacy Study. Ten rats per group were used in the study. Five groups of rats were prepared: AAV1/2-EV; adeno-associated virus serotype $1 / 2$ containing the mutated human A53T $\alpha$-synuclein gene (AAV1/2-hourA53T-aSyn) + vehicle (sterile water); AAV1/ 2-hourA53T-aSyn + trehalose (2\% in drinking water); AAV1/ 2-hourA53T-aSyn + trehalose $(0.89 \mathrm{~g} / \mathrm{kg}$, three times a day by mouth); and AAV1/2-hourA53T-aSyn + trehalose $(2.67 \mathrm{~g} / \mathrm{kg}$ per day, daily by mouth). In groups where trehalose was administered by oral gavage, it was delivered at a dose volume of $4 \mathrm{ml} / \mathrm{kg}$. Trehalose was delivered ad libitum (in drinking water), at $8 \mathrm{AM}, 4 \mathrm{PM}$, and $12 \mathrm{AM}$ (three times a day) or at $8 \mathrm{AM}$ (daily).

On day 1, all animals were fasted overnight and evaluated for forepaw use in the cylinder test to establish baseline performance. On day 1 , all animals received a unilateral injection of AAV1/2-hourA53TaSyn or AAV1/2-EV into the SN. Administration of trehalose or vehicle commenced on the day of surgery (day 1) and continued daily for 6 weeks. On days 20 and 41 all rats were fasted overnight and tested the following day for forepaw use in the cylinder test. On day 42 , rats were killed and blood and brain samples were taken.

$A A V 1 / 2$ vector delivery. AAV1/2 was administered at a volume of $2 \mu \mathrm{l}$ directly into the SN of one hemisphere (right side) using stereotactic techniques (anterior-posterior coordinate: $-5.2 \mathrm{~mm}$; medial-lateral coordinate: $-2 \mathrm{~mm}$ relative to Bregma; dorsal-ventral coordinate: $-7.5 \mathrm{~mm}$ relative to skull over $\mathrm{SN})$. The concentration of AAV1/2 used was $1.7 \times 10^{12}$ genomic particles $/ \mathrm{ml}$, which has previously been empirically determined by us to produce significant behavioral and dopaminergic nigrostriatal deficits between 3 and 6 weeks following surgical delivery (Koprich et al., 2011).

Behavioral analyses. Three and 6 weeks following AAV1/2 injection, spontaneous forepaw use was evaluated using the cylinder test. Briefly, rats with their right paws marked black were placed into a glass cylinder in front of two mirrors and they were video recorded. Videos were scored post hoc by an observer blinded to the treatment conditions. For each rearing by the animal, whether it used its left or right forepaw to touch the inner surface of the glass cylinder was recorded. Scoring was conducted over a period of 6 minutes. A minimum of 20 total touches was considered acceptable for inclusion in the analysis. The final data are presented as percentage of asymmetry [disparity between left paw use (contralateral to the injection) and right paw use (ipsilateral to the lesion)], which was derived from the following equation: [ $\%$ right paw use $)-(\%$ left paw use $) /(\%$ right paw use $)+(\%$ left paw use $)] \times 100$ (Whishaw and Kolb, 2005).

Postmortem tissue collection. On day 42 , rats received an overdose of pentobarbital ( $100 \mathrm{mg} / \mathrm{kg}$, i.p.) and were killed by exsanguination by way of transcardial perfusion with ice-cold $0.9 \%$ saline containing $0.1 \%$ heparin. Prior to perfusion, a blood sample $(\sim 500 \mu \mathrm{l})$ was collected via cardiac puncture into lithium/heparin-coated tubes. Blood samples were centrifuged at $1500 g_{\text {ave }}$ for 10 minutes at $4^{\circ} \mathrm{C}$ to deliver approximately $200 \mu \mathrm{l}$ of plasma, which was frozen immediately and stored at $-80^{\circ} \mathrm{C}$.

Brains were placed ventral-side up into an ice-cold, stainless steel rat brain matrix and cut in the coronal plane at the level of the optic chiasma. The brains were cut to produce two successive 1-mm-thick coronal slices. Each coronal slice was removed and the right and left striata were dissected and placed within individual Eppendorf tubes, frozen directly on dry ice and stored at $-80^{\circ} \mathrm{C}$ for high-performance liquid chromatography (HPLC) analysis. The cerebellum was removed, frozen in isopentane chilled to $-42^{\circ} \mathrm{C}$ and stored at $-80^{\circ} \mathrm{C}$ before being analyzed for trehalose by LC-MS/MS. The rostral portion of the brain, including the anterior striatum was immediately frozen in isopentane chilled to $-42^{\circ} \mathrm{C}$. The remainder of the caudal portion of the brain, including the mesencephalon, was immersed in $4 \%$ paraformaldehyde for 48 hours followed by cryoprotection in graded sucrose solutions (15\%-30\% sucrose) and used for tyrosine hydroxylase (TH) immunohistochemistry.
Striatal monoamine and metabolite levels. The two striata were dissected from each brain. The striata were weighed and homogenized in 10 volumes of $0.2 \mathrm{M}$ perchloric acid containing $100 \mu \mathrm{M}$ EDTA$2 \mathrm{Na}$ and $100 \mathrm{ng} / \mathrm{ml}$ isoproterenol [the internal standard for the measurement of catecholamine and 5-hydroxytryptamine contents using a tissue dismembrator (Fisher Scientific)]. Samples were centrifuged at $10,000 g_{\text {ave }}$ for 20 minutes at $4^{\circ} \mathrm{C}$. The solution of $1 \mathrm{M}$ sodium acetate was added to adjust the $\mathrm{pH}$ value to approximately 3.0. After filtration $(0.45 \mu \mathrm{m})$, the samples were injected into a HPLC system. Dopamine, dihydroxyphenylacetic acid (DOPAC), and homovanillic acid (HVA) were detected using a HPLC electrochemical detection system. Briefly, $20 \mu \mathrm{l}$ of the homogenate sample was injected into the HPLC electrochemical detection system using an L-2200 auto sampler (HITACHI, Tokyo, Japan) at $4^{\circ} \mathrm{C}$ and separated at $25^{\circ} \mathrm{C}$ on a reverse-phase analytical column (EICOMPAK SC-5ODS, $3.0 \times$ $150 \mathrm{~mm}$; Eicom, Kyoto, Japan). The analytes were then eluted at a flow rate of $0.5 \mathrm{ml} / \mathrm{min}$ at $30^{\circ} \mathrm{C}$ with $0.1 \mathrm{M}$ sodium acetate/citric acid (pH 5.4) containing $17 \%$ methanol, $190 \mathrm{mg} / \mathrm{l}$ sodium loctanesulfonate, and $5 \mathrm{mg} / \mathrm{l}$ EDTA-2Na. Levels of monoamines and their metabolites were then determined using a 2465 electrochemical detector (Waters, Milford, MA). The chromatograms were recorded and analyzed using a computer with Millennium 32 Chromatography Manager Software (Waters).

Tyrosine hydroxylase immunohistochemistry and stereology. Brains were sectioned frozen in the coronal plane at a thickness of $40 \mu \mathrm{m}$ on a freezing sliding microtome (Leica Microsystems Inc., Richmond Hill, ON, Canada) and six series of sections were stored in cryoprotectant (30\% glycerol, 30\% ethoxyethanol, 40\% PBS). A single series of sections was processed for visualization of TH via the biotinlabeled antibody procedure. Briefly, following several washes in a PBS solution containing $0.2 \%$ Triton X-100, endogenous peroxidase was quenched in a $3 \%$ hydrogen peroxide solution and background staining was inhibited in a $10 \%$ normal goat serum $/ 2 \%$ bovine serum albumin solution. Tissue was incubated with primary antibodies overnight: rabbit anti-TH antibody (1:1000; Pel-Freez, Rogers, AR). After three washes in PBS-Triton X-100, sections were sequentially incubated in biotinylated goat anti-rabbit or anti-mouse IgG (1:300; Vector, Burlingame, CA) for 1 hour and the Elite avidin-biotin complex (ABC Kits; Vector) for 1 hour separated by three washes in PBS. Immunostaining was visualized following a reaction with 3,3-diaminobenzidine (Vector). Sections were mounted on glass slides, allowed to dry, dipped into distilled $\mathrm{H}_{2} \mathrm{O}$, dehydrated through graded alcohols $(70 \%, 95 \%$, and $100 \%$ ), cleared in xylenes, and coverslipped with dibutyl phthalate xylene mounting medium (Electron Microscopy Sciences, Hatfield, PA).

The number of tyrosine hydroxylase positive $\left(\mathrm{TH}^{+\mathrm{ve}}\right)$ cells within the SN pars compacta was performed using Stereo Investigator software (MBF Bioscience, Williston, VT) according to stereologic principles. Eight sections, each separated by $240 \mu \mathrm{m}$ from the anterior to the posterior SN, were used for counting each case. Stereology was performed using a Zeiss microscope (Carl Zeiss) coupled to a digital camera for visualization of tissue sections. The total number of positive neurons was estimated from coded slides using the optical fractionator method. For each tissue section analyzed, section thickness was assessed empirically and guard zones of $\sim 2 \mu \mathrm{m}$ thickness were used at the top and bottom of each section. The SN pars compacta was outlined under low magnification $(5 \times)$ and $\mathrm{TH}^{+\mathrm{ve}}$ cells were counted under $40 \times$ magnification. Stereological parameters were empirically determined (i.e., grid size, counting frame size, and dissector height) using Stereo Investigator software (MicroBrightfield, Williston, VT). The acceptable coefficient of error was calculated according to the procedure of West and colleagues (1991), known as the Gunderson coefficient of error $(m=1)$. Gunderson values $<0.10$ were accepted.

$\alpha$-Synuclein assessment. After removing the brain rapidly, the tissues were separated from the brain and then homogenized on ice with a microcontent motor-operated tissue homogenizer (Kimblekonts) in ice-cold lysis buffer ( $1 \times$ PBS, $1 \%$ Nonidet P-40, $0.5 \%$ sodium deoxycholate, and $0.1 \%$ SDS radioimmunoprecipitation assay buffer) 
supplemented with protease inhibitors. Lysates were centrifuged at $10,000 g_{\text {ave }}$ for 20 minutes at $4^{\circ} \mathrm{C}$ and the supernatants were collected. Protein concentrations were determined by a Bradford protein assay. Equal amounts of protein $(30 \mu \mathrm{g})$ were separated by SDS-PAGE and electroblotted onto nitrocellulose filter membrane (Millipore). After nonspecific antibody binding was blocked with 5\% nonfat dry milk, membranes were incubated at $4^{\circ} \mathrm{C}$ overnight with human $\alpha$-synuclein (1:500; Zymed, San Francisco, CA) and monoclonal rabbit anti- $\beta$-actin (1:8000; Epitomics). After washing in Tris-buffered saline/Tween 20, the immunoblots were incubated with horseradish peroxidase-conjugated secondary antibodies (Cell Signaling Technology) for 1 hour. The immunoblots were developed with enhanced chemiluminescence reagents (Millipore) and measured with Quantity Software (Bio-Rad, CA). To compare protein loading, antibody directed against $\beta$-actin was used.

Pharmacokinetic Study. Ninety Sprague-Dawley rats (54 females, 36 males) received trehalose $(2.67 \mathrm{~g} / \mathrm{kg}$, daily by mouth) for 1 or 7 days. Groups of five rats (three females, two males) were anesthetized under carbon dioxide for sample collection at the following time points: predose, $0.25,0.5,1,1.5,2,3,4,8$, and 12 hours postdose on days 1 and 7 . Blood samples (at least $800 \mu \mathrm{l}$ ) were collected via jugular vein into lithium-heparinized tubes. The tubes were gently inverted several times to ensure mixing. Whole blood was processed by centrifugation at $3200 g_{\text {ave }}$ for 10 minutes. Plasma samples $(\sim 400 \mu \mathrm{l})$ were collected and kept at $-80^{\circ} \mathrm{C}$ prior to analysis. Immediately after blood collection, the whole brain was quickly removed and rinsed with cold saline, and surface vasculature was ruptured and blotted with dry tissue. The whole brain was dissected in two by a midsagittal cut through the corpus callosum and one-half of the brain was homogenized with 3 -fold volume of $0.1 \mathrm{~mol} / \mathrm{l} \mathrm{PBS}(\mathrm{w} / \mathrm{v})$ in an ice bath. Homogenized tissue sample was stored below $-80^{\circ} \mathrm{C}$ prior to analysis. The other hemisphere was frozen in isopentane chilled to $-42^{\circ} \mathrm{C}$ and stored at $-80^{\circ} \mathrm{C}$. Plasma and brain samples were analyzed for trehalose levels using a validated LC-MS/MS method. Pharmacokinetic parameters were calculated using a noncompartmental model (Pharsight Phoenix 6.3).

\section{Macaque Studies}

Efficacy Study. Twenty-five female cynomolgus macaques were split into three groups ( $N=8$ to 9/group): AAV1/2-EV; AAV1/2hourA53T-aSyn + vehicle (sterile water); and AAV1/2-hourA53TaSyn + trehalose $(2.67 \mathrm{~g} / \mathrm{kg}$ per day, by mouth). On day 1 of the study, the macaques received bilateral injections of AAV1/2-hourA53T-aSyn or AAV1/2-EV into the SN (four sites per side). Commencing on day 2, macaques received 20 weeks of once-daily oral administration of vehicle or trehalose. On day 142, macaques received a final administration of trehalose and 1 hour later macaques were killed and blood, cerebrospinal fluid (CSF), and brain samples were taken.

AAV1/2 vector delivery. A single T1-weighted 3T magnetic resonance imaging scan was obtained of each animal prior to surgery and used to calculate surgical coordinates for each macaque and each target. During the procedure, macaques were sedated with Zoletil (4-6 mg/kg, i.m.) and atropine $(0.04 \mathrm{mg} / \mathrm{kg}$, i.m.). Once sedated, macaques were mounted onto the surgical frame (model 1530M; Kopf Instruments) and coordinates were recorded to subsequently allow placement of the macaque back into the frame at the same orientation for surgery. Once in the frame, the macaque was placed into the magnetic resonance imaging scanner (3T, General Electric) and 0.3-mm-thick horizontal slices were obtained throughout the brain. Images were stored on external hard drives and interrogated using Osirix imaging software for viewing and derivation of surgical targets, such that for each hemisphere the four injection sites were within the SN pars compacta along its entire rostro-caudal extent. Part of this process included a qualitative inspection of the brain to note any abnormal neuroanatomical presentations (e.g., tumor, abnormal asymmetry).

Stereotaxic injection of AAV1/2 vectors (either AAV1/2-hourA53TaSyn or AAV1/2-EV) was performed under isoflurane anesthesia
( $2 \%$ in $2 \mathrm{l} / \mathrm{min} \mathrm{O}_{2}$ ) under sterile conditions. All cranial injections were performed with the macaque in a stereotactic head holder (David Kopf Instruments). Precise stereotaxic coordinates for all surgeries were calculated prior to surgery from each individual macaque magnetic resonance imaging scan. Following sterile preparation, incisions were made in the scalp over the target area and skin, muscle, and fascia were retracted to expose the cranial surface. Single bilateral burr holes were made over the target areas using a surgical drill. A small incision was then made in the dura mater above the desired injection sites and the tip of a Hamilton syringe (26G; Hamilton Company) was lowered to each of the desired sites for microinjection. Injections containing AAV1/2-hourA53T-aSyn or AAV1/2-EV were made at a speed of $2 \mu \mathrm{l} / \mathrm{min}$ and a volume of $7 \mu \mathrm{l}$ (at a viral titer of $1.7 \times 10^{12}$ active particles per milliliter) each into four sites of each hemisphere of the SN. The needle was maintained in place for an additional 5 minutes after injection before being withdrawn very slowly and moved to the next site. Following injection, the exposed dura was covered with Gelfoam (Pfizer Canada) and the incision was closed with an interrupted 6-0 monofilament suture. Macaques received antibiotic treatment immediately prior to surgery (ampicillin, $160 \mathrm{mg} / \mathrm{kg}$, i.m.) and twice daily thereafter for 3 days. Postoperatively, for pain management macaques received tramadol ( $3 \mathrm{mg} / \mathrm{kg}$, i.m.) twice daily for 3 days and meloxicam $(0.1 \mathrm{mg} / \mathrm{kg}$, by mouth) once daily for 5 days. Throughout the surgical procedure the animals were carefully monitored for changes in heart rate, pulse oximetry, and body temperature.

Behavioral analysis. Prior to surgery, during weeks $-3,-2$ and -1 , and after surgery during weeks $3,6,9,12,15$, and 18 of trehalose treatment behavior was recorded for a period of 4 hours, with animals housed in individual observation cages. Behavioral observations were conducted between 9.00 PM and 1.00 PM, off treatment, starting 4 hours prior to daily trehalose dosing at 1.00 PM. On completion of the observation period, the animals were returned to group housing in their home cages. A quantitative assessment of activity was attained using computer-based activity monitors. Movement of the animal was assessed by a passive infrared detector. Activity counts were cumulated into each hour of analysis.

Striatal monoamine and metabolite levels. Punched tissue dissections of putamen were individually homogenized in 200-750 $\mu \mathrm{l}$ of trichloroacetic acid $(0.1 \mathrm{M})$ containing sodium acetate $(10 \mathrm{mM})$, EDTA $(0.1 \mathrm{mM})$, and methanol (10.5\%, $\mathrm{pH} 3.8)$ using a tissue dismembrator (Fisher Scientific). The level of catecholamines was then measured as in the rodent study.

Striatal dopamine transporter binding. The levels of striatal dopamine transporter (DAT) were assessed by $3 \beta-\left(4-\left[{ }^{125} \mathrm{I}\right]\right.$ iodophenyl) tropan- $2 \beta$-carboxylic acid isopropyl ester binding autoradiography in cryostat cut sections prepared from $20 \mu \mathrm{m}$ fresh-frozen tissue. Briefly, thawed slides were placed in binding buffer $(2 \times 15$ minutes at room temperature) containing Tris ( $50 \mathrm{mM}), \mathrm{NaCl}(120 \mathrm{mM})$, and $\mathrm{KCl}(5 \mathrm{mM})$. Sections were then placed in the same buffer containing $3 \beta-\left(4-{ }^{125} \mathrm{I}\right]$ iodophenyl)tropan- $2 \beta$-carboxylic acid isopropyl ester $(50 \mathrm{pM}$, specific activity $2200 \mathrm{Ci} / \mu \mathrm{mol}$; Perkin-Elmer) for 120 minutes at $25^{\circ} \mathrm{C}$ to determine total binding. Nonspecific binding was defined as that observed in the presence of 1-\{2-[bis-(4-fluorophenyl)methoxy]ethyl\}-4(3-phenylpropyl)-piperazine ( $100 \mu \mathrm{M}$; Tocris Bioscience). All slides were then washed ( $4 \times 15$ minutes) in ice-cold binding buffer, rinsed in icecold distilled water, and air dried. Together with $\left[{ }^{125} \mathrm{I}\right]$-microscale standards (Amersham), slides were then apposed to autoradiographic film (Kodak) and left for $\sim 7$ days at room temperature before developing. Autoradiograms were then analyzed using MCID software (Image Research Inc, Ontario, Canada). Densitometric analysis of three striata from each animal was carried out, whereby a reference curve of counts per minute versus optical density is calculated from $\beta$-emitting $\left[{ }^{14} \mathrm{C}\right]$ microscale standards and used to quantify the intensity of signal as nanocuries/gram tissue. Background intensity was subtracted from each reading. Nonspecific binding was calculated in the same way and subtracted from the total to give specific binding. Nonspecific binding was $<1 \%$ of total binding. 
Tyrosine hydroxylase immunohistochemistry and stereology. Postfixed sections of mesencephalon were processed for tyrosinehydroxylase $\left(\mathrm{TH}^{+\mathrm{ve}}\right)$ immunocytochemistry. Brains were cut frozen in the coronal plane at a thickness of $40 \mu \mathrm{m}$ on a microtome (Leica) and 12 series of sections were stored in cryoprotectant. Onetwelfth of the series of sections were processed for visualization of $\mathrm{TH}$ via the biotin-labeled antibody procedure. Briefly, following several washes in a PBS solution containing Triton X-100 (0.5\%), endogenous peroxidase was quenched in hydrogen peroxide solution and background staining was inhibited in a $10 \%$ normal goat serum $/ 2 \%$ bovine serum albumin solution. Tissue was then incubated overnight with rabbit anti-TH antibody (1:5000; Chemicon International). After three washes in Triton X-100/PBS, sections were sequentially incubated in biotinylated anti-rabbit IgG raised in goat (1:400; Vector Laboratories) for 2 hours and the Elite avidin-biotin complex (ABC Kits; Vector Laboratories) for 1 hour, separated by three washes in PBS. TH immunostaining was visualized following a reaction with ImmPACT DAB chromagen (Vector Laboratories). Sections were then mounted on glass slides and cover slipped with dibutyl phthalate xylene mounting medium. Estimates of $\mathrm{TH}^{+\mathrm{ve}}$ neuronal number within the $\mathrm{SN}$ was performed as outlined in the rodent study with the following differences: sections were separated by $480 \mu \mathrm{m}$ and approximately $4 \%$ of the $\mathrm{SN}$ was analyzed.

$\alpha$-Synuclein assessment. Punched tissue dissections of putamen were individually homogenized using a $4 \mathrm{X}$ volume of cold Dulbecco's PBS (Invitrogen, Burlington, ON, Canada) supplemented with 1X protease inhibitor cocktail, followed by the addition of guanidine $\mathrm{HCl}$ $(8.2 \mathrm{M}) /$ Tris-HCl $(82 \mathrm{mM}, \mathrm{pH} 8.0)$ to yield a solution with a final guanidine concentration of $5 \mathrm{M}$. Samples were sonicated (QSonica, Newtown, CT) at $70 \%$ for 10 seconds per time. The homogenates were then placed in an orbital shaker for 3 hours at room temperature before centrifuging at $16,000 g_{\text {ave }}$ for 20 minutes at $4^{\circ} \mathrm{C}$. Supernatants were aliquoted and frozen at $-80^{\circ} \mathrm{C}$. The BCA Protein Assay Kit was used to measure total protein concentration (Pierce Thermo Scientific). Levels of aSyn were determined using the human $\alpha$-Synuclein ELISA Kit (Invitrogen). Kit components were equilibrated to reach room temperature before reconstitution and dilution of the aSyn standards. All samples were diluted to a concentration of $0.4872 \mathrm{mg} / \mathrm{ml}$. Standards and samples were then added to each sample well $(50 \mu \mathrm{l})$. After incubation with human aSyn detection antibody for 3 hours at room temperature, the plate was washed four times with $1 \times$ wash buffer. The anti-rabbit IgG horseradish peroxidase antibody was added to each well and allowed to incubate for 30 minutes at room temperature. Following incubation, the plate was then washed four times with $1 \times$ wash buffer and $100 \mu \mathrm{l}$ of the stabilized chromogen was added to each well and incubated in the dark for 25 minutes at room temperature. The reaction was halted and optical density values were determined at $450 \mathrm{~nm}$.

Pharmacokinetics. Three female cynomolgus macaques were used. Trehalose (2.67 and $5.34 \mathrm{~g} / \mathrm{kg}$ per day, by mouth) was administered once a day for 7 days with a 14-day washout between the different dosing regimens. On days 1 and 7 , blood samples were collected predose (5 minutes before dosing) and at $0.25,0.5,1,2,4,6$, 12 , and 24 hours postdose. Following a second 14-day washout, animals were readministered trehalose ( $2.67 \mathrm{~g} / \mathrm{kg}$ per day, by mouth) for 2 days. On day 1 blood samples were collected predose (5 minutes before dosing) and at $0.25,0.5,1,2,4,6,12$, and 24 hours postdose. On day 2, the animals were killed at 1 hour postdose and blood, CSF, and brain samples were collected.

Blood samples (at least $500 \mu \mathrm{l}$ ) were collected via the saphenous vein into sodium-heparinized tubes. The tubes were centrifuged at $1500 g_{\text {ave }}$ and the resulting plasma layers were removed and stored at $-80^{\circ} \mathrm{C}$ prior to analysis. Plasma, CSF, and brain samples were analyzed for trehalose levels using a validated LC-MS/MS method. Pharmacokinetic parameters were calculated using a noncompartmental model (Pharsight Phoenix 6.3).

\section{Data Analysis}

Data were expressed as mean \pm S.E.M. Mean differences between the groups were analyzed using one-way ANOVA followed by Fisher's protected least-significant difference test using GraphPad Prism (version 7.02).

\section{Results}

\section{Rodent Efficacy Study}

Effects of AAV1/2-HourA53T-aSyn on Behavior, Dopaminergic Markers, and aSyn Expression. Rats receiving AAV1/2-hourA53T-aSyn exhibited forelimb asymmetry, an indication of parkinsonism, as measured by the cylinder test on day $21(51 \% \pm 15 \%$ asymmetry) and day $42(52 \% \pm 21 \%$ asymmetry) compared with rats receiving AAV1/2-EV on day $21(8 \% \pm 9 \%)$ and day $42(15 \% \pm 7 \%$ asymmetry $)$, respectively (Fig. 1, A and B), although this asymmetry only reached significance on day 21. Postmortem analysis demonstrated that rats receiving AAV1/2-hourA53T-aSyn had a significantly lower level of striatal dopamine, expressed as a percentage of the contralateral side $(42.4 \% \pm 5.8 \%)$ compared with rats receiving AAV1/2-EV (123.8\% $\pm 6.8 \%)$ (Fig. 1C). There were no significant changes in striatal levels of the dopamine metabolites DOPAC and HVA; however, dopamine turnover (DOPAC + HVA: dopamine) was significantly higher in rats receiving AAV1/2-hourA53T-aSyn compared with rats receiving AAV1/2-EV $(172.5 \% \pm 25.8 \%$ compared with 93.3\% $\pm 3.3 \%$ ) (Fig. 1D). In addition, rats receiving AAV1/ 2-hourA53T-aSyn had fewer $\mathrm{TH}^{+\mathrm{ve}}$ cells in the $\mathrm{SN}(6909 \pm$ 535 compared with $4440 \pm 536$ ) (Fig. $1 \mathrm{~F}$ ) and a higher striatal level of aSyn $(1.3360 \pm 0.1530$ compared with $0.0157 \pm$ 0.0079) compared with rats receiving AAV1/2-EV (Fig. 1E).

Single Daily Administration of Trehalose Increases Striatal Dopamine and Reduces Behavioral Asymmetry Compared with the Same Daily Dose Administered in Drinking Water or as Three Administrations. Rats receiving AAV1/2-hourA53T-aSyn and treated with trehalose $(2.67 \mathrm{~g} / \mathrm{kg}$ per day) exhibited less forelimb asymmetry compared with rats receiving AAV1/2-hourA53T-aSyn and vehicle, as measured by the cylinder test on day $21(12 \% \pm 17 \%$ compared with $51 \% \pm 15 \%)$ and day $42(4 \% \pm 15 \%$ compared with $52 \pm 21$ ) (Fig. 1, A and B), although this only reached significance on day 42 . By contrast, rats receiving the same daily amount of trehalose, either administered as a $2 \%$ solution in drinking water or as three administrations of $0.89 \mathrm{~g} / \mathrm{kg}$ per day 8 hours apart, did not exhibit less forelimb asymmetry.

Postmortem analysis found that rats receiving AAV1/ 2-hourA53T-aSyn and treated with trehalose $(2.67 \mathrm{~g} / \mathrm{kg}$ per day) had a significantly higher striatal dopamine level compared with rats receiving AAV1/2-hourA53T-aSyn and vehicle $(65.4 \% \pm 7.5 \%$ compared to $42.4 \% \pm 5.8 \%)$ (Fig. 1C). Furthermore, rats receiving trehalose either in the drinking water or as three administrations did not have significantly higher striatal dopamine levels compared with rats receiving vehicle (Fig. 1C). Trehalose treatment by any route of administration did not alter striatal levels of DOPAC or HVA or alter turnover. Trehalose treatment, by any route, did not significantly alter the number of $\mathrm{TH}^{+\mathrm{v} e}$ cells in the $\mathrm{SN}$, nor did it significantly reduce the amount of aSyn in the striatum (Fig. 1, E and F). 
A

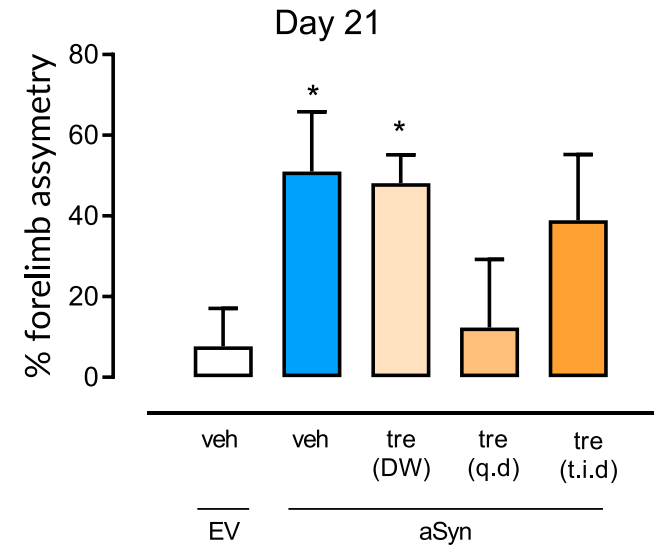

C
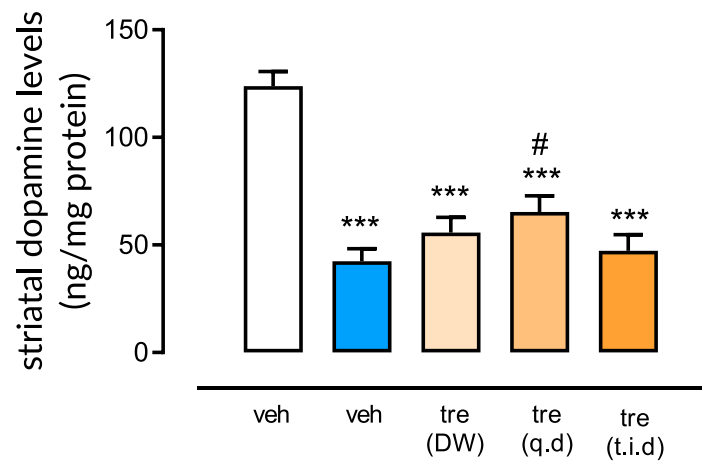

$\overline{\mathrm{EV}}$

E

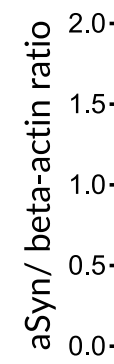

B

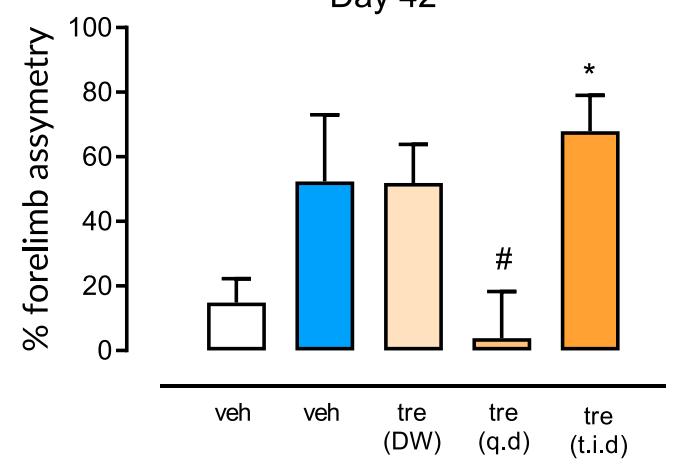

EV
Day 42



F

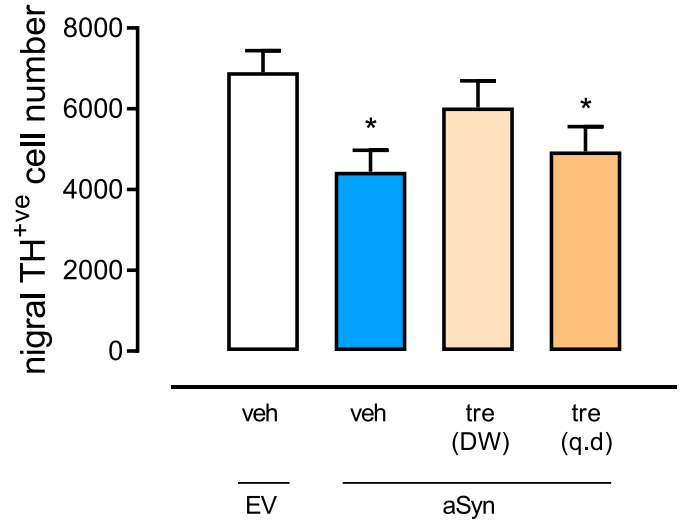

Fig. 1. Effect of repeated oral administration of trehalose on behavior, aSyn load, and markers of dopaminergic signaling in the AAV1/2-hourA53T-aSyn rat. Trehalose $(2.67 \mathrm{~g} / \mathrm{kg}$ per day) was administered in drinking water [(DW), $2 \% \mathrm{w} / \mathrm{v}]$, as three separate administrations 8 hours apart $(0.89 \mathrm{~g} / \mathrm{kg}$ three times a day, by mouth) or as a single administration $(2.67 \mathrm{~g} / \mathrm{kg}$ daily, by mouth) for 6 weeks. Trehalose, given as a single daily administration, significantly reduced forelimb asymmetry measured in a cylinder test (A and B) and AAV1/2-hourA53T-aSyn induced loss of dopamine (C). Trehalose, given as a single daily administration, also reduced dopamine turnover to a level not significantly different from rats receiving AAV1/2-EV (D), but did not prevent $\mathrm{TH}^{+\mathrm{ve}}$ cell loss in the $\mathrm{SN}(\mathrm{F})$. Trehalose administered in drinking water did not reduce forelimb asymmetry (A and $\mathrm{B}$ ) or increase striatal dopamine (C), but did reduce striatal dopamine turnover and nigral $\mathrm{TH}^{+\mathrm{ve}}$ cell loss to a level not significantly different from rats receiving AAV1/2-EV (D and F). Trehalose administered as three separate administrations 8 hours apart did not alter any endpoint measured. None of the trehalose treatments altered aSyn expression in the striatum (E). Data are mean \pm S.E.M., $N=5-8$ rats/group. $* P<0.05$, ${ }^{* *} P<0.01, * * * P<0.001$ vs. AAV1/2-EV, " $P<0.05$ vs. AAV1/2-hourA53T-aSyn. One-way ANOVA followed by Fisher's least-significant difference post hoc test.

Terminal plasma and brain samples were collected and analyzed for trehalose. Trehalose plasma levels were below the limit of quantification in rats receiving trehalose in the drinking water. Trehalose was measurable in the plasma 30 minutes after receiving trehalose by oral gavage; $0.89 \mathrm{~g} / \mathrm{kg}$ per day, three times a day, produced a plasma trehalose level of $1131 \pm 178 \mathrm{ng} / \mathrm{ml}$ and $2.67 \mathrm{~g} / \mathrm{kg}$ per day produced a plasma trehalose level of $6383 \pm 890 \mathrm{ng} / \mathrm{ml}$. Trehalose was only measurable in the brain of rats receiving single daily doses of trehalose and produced a brain level of $53 \pm 17 \mathrm{ng} / \mathrm{ml}$.

\section{Rodent Pharmacokinetic Study}

Trehalose $(2.67 \mathrm{~g} / \mathrm{kg}$ per day, by mouth) provided the most robust efficacious response in the AAV1/2-hourA53T-aSyn rat. Therefore, a study was performed to define the plasma and 
brain pharmacokinetics associated with an efficacious dose of trehalose $(2.67 \mathrm{~g} / \mathrm{kg}$ per day, by mouth). Following single oral administration of trehalose, there was a rapid increase in plasma trehalose that peaked 15 minutes after administration and declined rapidly, being undetectable at 4 hours postdose (Fig. 2A). The plasma $C_{\max }$, area under the curve from time 0 to infinity $\left(\mathrm{AUC}_{0-\text { inf }}\right)$, and half-life $\left(t_{1 / 2}\right)$ values were $8900 \mathrm{ng} / \mathrm{ml}, 11,136$ hour.ng/ml, and 0.76 hours, respectively. Brain trehalose exposure followed the same time course as plasma exposure (Fig. 2B) and was approximately $1 \%$ of the plasma trehalose level. The brain $C_{\max }, \mathrm{AUC}_{0-\text { inf }}$, and $t_{1 / 2}$ values were $87 \mathrm{ng} / \mathrm{ml}, 97$ hour. $\mathrm{ng} / \mathrm{ml}$, and 0.81 hours, respectively. Following 7 days of trehalose administration, there was no accumulation of trehalose, with the pharmacokinetic profile being very similar on days 1 and 7 (Fig. 2C).

\section{NHP Pharmacokinetic Study}

Trehalose (2.67 and $5.34 \mathrm{~g} / \mathrm{kg}$ per day, by mouth) was administered to three female macaques for 7 days. Similar to the pharmacokinetic profile in rats, there was a rapid increase in plasma trehalose exposure that peaked at $\sim 1$ hour postdose and then declined. The decline in plasma exposure was less rapid than in rats, with trehalose being detectable up to 12 hours postdose (Fig. 3, A and B). Following single administration of trehalose $(2.67 \mathrm{~g} / \mathrm{kg})$, the plasma $C_{\max }$, $\mathrm{AUC}_{0-\text { inf }}$, and $t_{1 / 2}$ values were $10,918 \mathrm{ng} / \mathrm{ml}, 27,445$ hour.ng/ml, and 1.1 hours, respectively, and following single administration of trehalose $(5.63 \mathrm{~g} / \mathrm{kg})$, the plasma $C_{\max }, \mathrm{AUC}_{0-\mathrm{inf}}$, and $t_{1 / 2}$ values were $36,962 \mathrm{ng} / \mathrm{ml}, 80,040$ hour.ng/ml, and 1.8 hours, respectively. Following 7 days of trehalose administration, there was no accumulation of trehalose in the plasma, with the pharmacokinetic profile being similar on days 1 and 7 (Fig. 3C). Trehalose (2.67 g/kg per day, by mouth) produced brain and CSF exposures of $81.3 \pm 13.8 \mathrm{ng} / \mathrm{g}$ and $562 \pm$ $346.5 \mathrm{ng} / \mathrm{ml}$, respectively. A daily oral trehalose dose of 2.67 $\mathrm{g} / \mathrm{kg}$ per day produced a plasma pharmacokinetic profile that was similar to, but slightly greater than, the dose of trehalose that was associated with efficacy in the rat $(2.67 \mathrm{~g} / \mathrm{kg}$ per day, by mouth); therefore, this dose was used in the subsequent NHP efficacy study.

\section{NHP Efficacy Study}

Effects of AAV1/2-HourA53T-aSyn on Dopaminergic Lesion, aSyn Expression, and Behavior. Macaques receiving AAV1/2-hourA53T-aSyn had a significantly lower level of putamenal dopamine (79 $\pm 13 \mathrm{ng} / \mathrm{mg}$ protein) (Fig. 4A) and DAT (274 $\pm 36 \mathrm{nCi} / \mathrm{g}$ tissue) (Fig. 4C) compared with macaques receiving AAV1/2-EV (dopamine, $160 \pm 7 \mathrm{ng} / \mathrm{mg}$ protein; DAT,
A

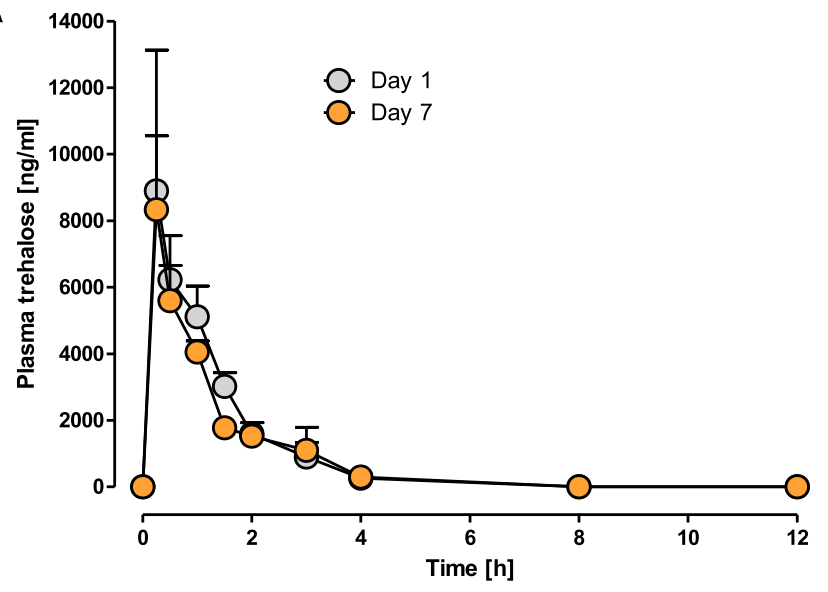

B

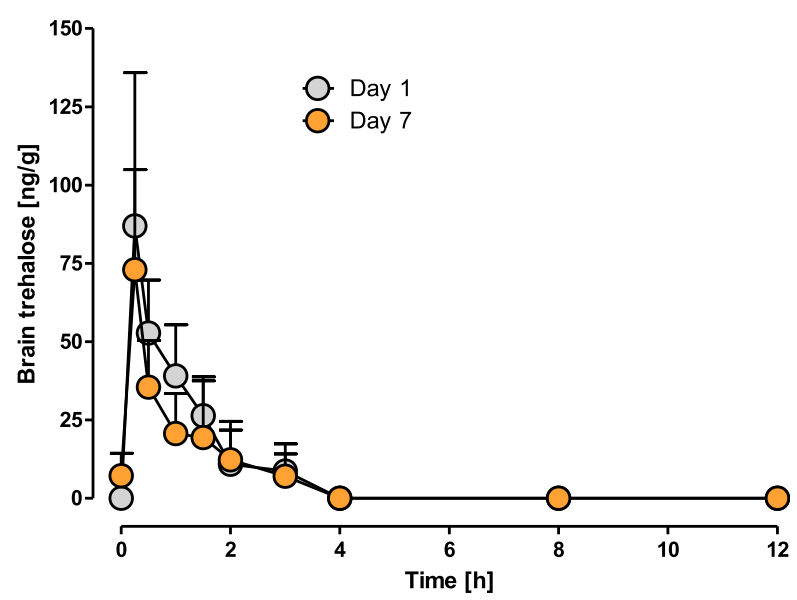

C

\begin{tabular}{lllll}
\hline \multirow{2}{*}{ PK parameter } & Day 1 & Day 7 & Day 1 & Day 7 \\
\hline $\mathrm{T}_{\max }(\mathrm{h})$ & 0.25 & 0.25 & 0.25 & 0.25 \\
$\mathrm{C}_{\max }(\mathrm{ng} / \mathrm{ml})$ & 8900 & 8336 & 87.0 & 73.0 \\
$\mathrm{AUC}_{0-12 \mathrm{~h}}(\mathrm{~h} . \mathrm{ng} / \mathrm{ml})$ & 10851 & 9494 & 86.8 & 65.3 \\
$\mathrm{AUC}_{0-\mathrm{inf}}(\mathrm{h} . \mathrm{ng} / \mathrm{ml})$ & 11136 & 9876 & 97.0 & 76.2 \\
$\mathrm{t}_{1 / 2}(\mathrm{~h})$ & 0.76 & 0.89 & 0.81 & 1.06 \\
\hline
\end{tabular}

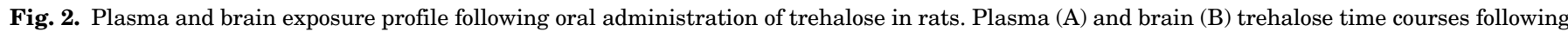

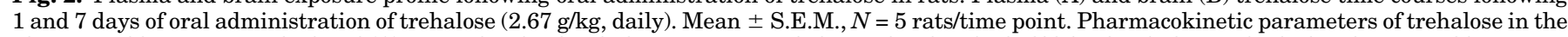

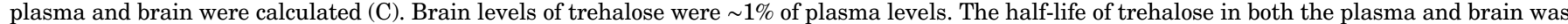

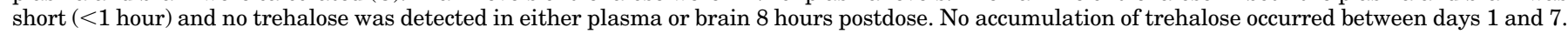



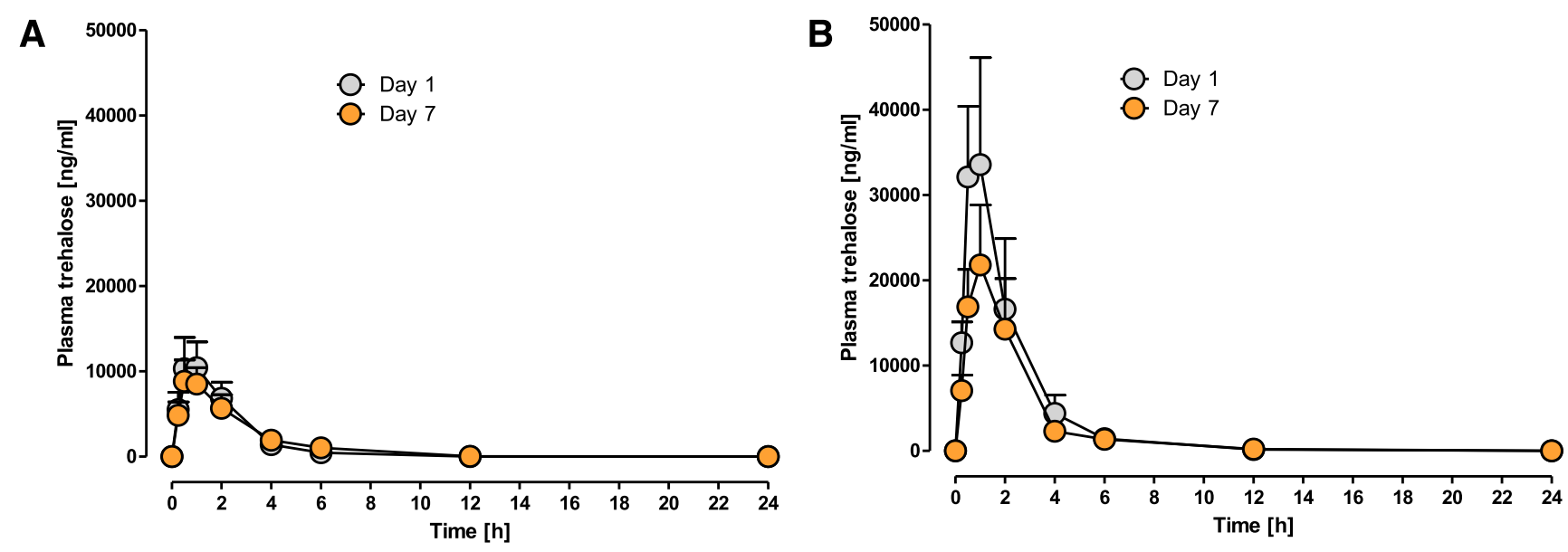

C

\begin{tabular}{|c|c|c|c|c|}
\hline \multirow[b]{2}{*}{ PK parameter } & \multicolumn{2}{|c|}{$2.67 \mathrm{~g} / \mathrm{kg} / \mathrm{day}$} & \multicolumn{2}{|c|}{$5.34 \mathrm{~g} / \mathrm{kg} /$ day } \\
\hline & Day 1 & Day 7 & Day 1 & Day 7 \\
\hline $\mathrm{T}_{\max }(\mathrm{h})$ & 0.83 & 0.67 & 0.67 & 0.83 \\
\hline $\mathrm{C}_{\max }(\mathrm{ng} / \mathrm{ml})$ & 10918 & 9578 & 36962 & 22444 \\
\hline $\mathrm{AUC}_{0-24 \mathrm{~h}}(\mathrm{~h} . \mathrm{ng} / \mathrm{ml})$ & 26657 & 26023 & 78899 & 56483 \\
\hline $\mathrm{AUC}_{0 \text {-inf }}(\mathrm{h} . \mathrm{ng} / \mathrm{ml})$ & 27445 & 27363 & 80040 & 57172 \\
\hline$t_{1 / 2}(h)$ & 1.1 & 1.5 & 1.8 & 2.3 \\
\hline
\end{tabular}

Fig. 3. Plasma exposure profile following oral administration of trehalose in macaques. Plasma trehalose time courses following 1 and 7 days of daily oral administration of trehalose at $2.67 \mathrm{~g} / \mathrm{kg}$ (A) or $5.63 \mathrm{~g} / \mathrm{kg}(\mathrm{B})$. Mean \pm S.E.M., $N=3$ macaques. Pharmacokinetic parameters of trehalose in the plasma were calculated (C). The half-life of trehalose in the plasma was short, although longer than in rats. No trehalose was detected in the plasma 8 hours postdose. No accumulation of trehalose occurred between days 1 and 7 .

$494 \pm 52 \mathrm{nCi} / \mathrm{g}$ tissue). AAV1/2-hourA53T-aSyn also produced a significant reduction in putamenal HVA compared to $\mathrm{EV}$ (141 \pm 11 compared to $188 \pm 16 \mathrm{ng} / \mathrm{mg}$ protein, respectively) (Fig. 4B), but did not significantly alter putamenal DOPAC or dopamine turnover. Macaques receiving AAV1/2-hourA53TaSyn had fewer $\mathrm{TH}^{+\mathrm{ve}}$ cells in the SN (59,513 \pm 7720 compared to $95,678 \pm 7799$ ) (Fig. 4D) and higher striatal levels of aSyn $(55,455 \pm 5120$ compared to $36,394 \pm 2362 \mathrm{ng} / \mathrm{mg}$ protein $)$ (Fig. 4E) compared with macaques receiving AAV1/2-EV. Macaques receiving AAV1/2-hourA53T-aSyn exhibited motor activity levels that were not significantly different from macaques receiving AAV1/2-EV.

Single Daily Administration of Trehalose Increases Putamenal Dopamine and DAT in AAV1/2-HourA53TaSyn Lesioned Macaques. Macaques receiving AAV1/ 2-hourA53T-aSyn and treated with trehalose $(2.67 \mathrm{~g} / \mathrm{kg}$ per day) had significantly higher putamenal dopamine $(110 \pm$ 8 compared to $79 \pm 13 \mathrm{ng} / \mathrm{mg}$ protein) (Fig. $4 \mathrm{~A}$ ) and DAT ( $411 \pm 48$ compared with $274 \pm 36 \mathrm{nCi} / \mathrm{g}$ tissue) (Fig. 4C) levels compared with macaques receiving AAV1/2-hourA53T-aSyn and vehicle. Trehalose treatment did not significantly alter putamenal HVA or DOPAC levels or putamenal dopamine turnover. Moreover, trehalose treatment did not alter the number of $\mathrm{TH}^{+\mathrm{ve}}$ cells in the $\mathrm{SN}$, the amount of aSyn in the striatum, or motor activity (Figs. 4, B, D, and E).

\section{Discussion}

The current studies were designed to evaluate the potential of trehalose to be developed as a disease-modifying treatment of PD and to address dosing and exposure knowledge gaps that are an impediment to developing trehalose. Previous studies have demonstrated the potential of trehalose as a treatment of PD. Thus, administration of trehalose ad libitum in drinking water $(2 \% \mathrm{w} / \mathrm{v})$ has been shown, in MPTP-lesioned mice, to prevent loss of DAT and TH staining in the striatum and SN, and to prevent dopamine loss in the striatum (Sarkar et al., 2014). Similar results were obtained in the same model by Ferguson et al., (2015) when a lower dose of trehalose (1\% w/v in drinking water) was used, with significant prevention of dopamine loss and the number of $\mathrm{TH}^{+\mathrm{ve}}$ cells in the $\mathrm{SN}$, although in that study trehalose did not alter MPTP-induced behavioral abnormalities.

Trehalose is also efficacious in animal models based on aSyn overexpression. In transgenic mice that overexpress hA53T $\alpha$-synuclein, administration of trehalose in drinking water (2\% w/v) caused an increase in LC3 II, a marker of autophagy, and decreased the brain level of insoluble aSyn (Tanji et al., 2015), although the total amount of brain aSyn was unaltered. In previous work, in an AAV1/2-hourA53T-aSyn-based rat model of $\mathrm{PD}$, we demonstrated that trehalose in drinking water $(2 \%$ and $5 \% \mathrm{w} / \mathrm{v})$ for 3 or 6 weeks attenuated behavioral 
A

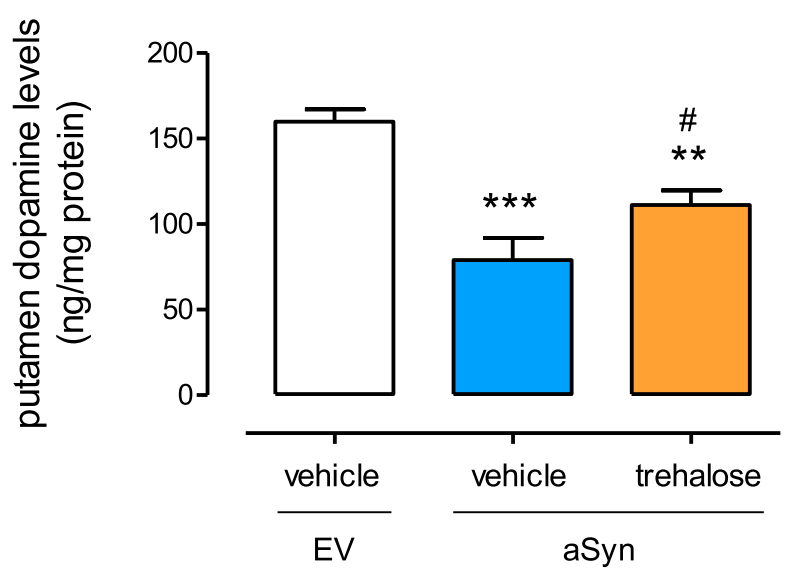

C

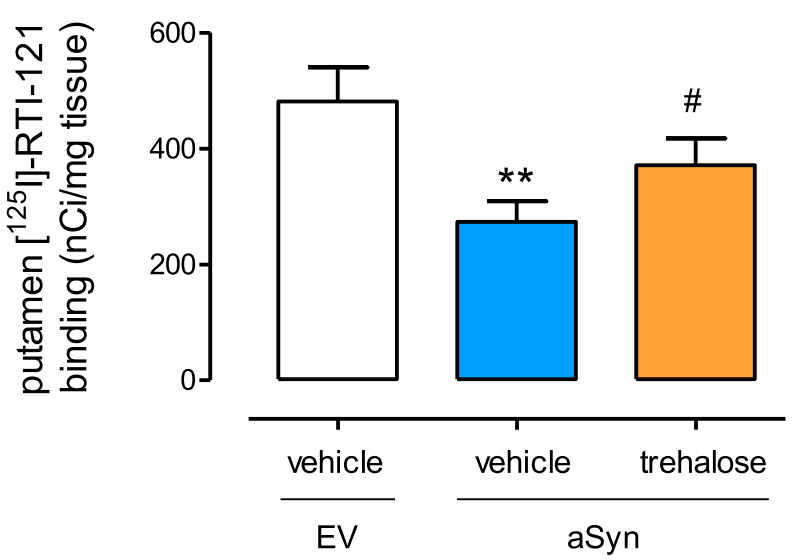

E

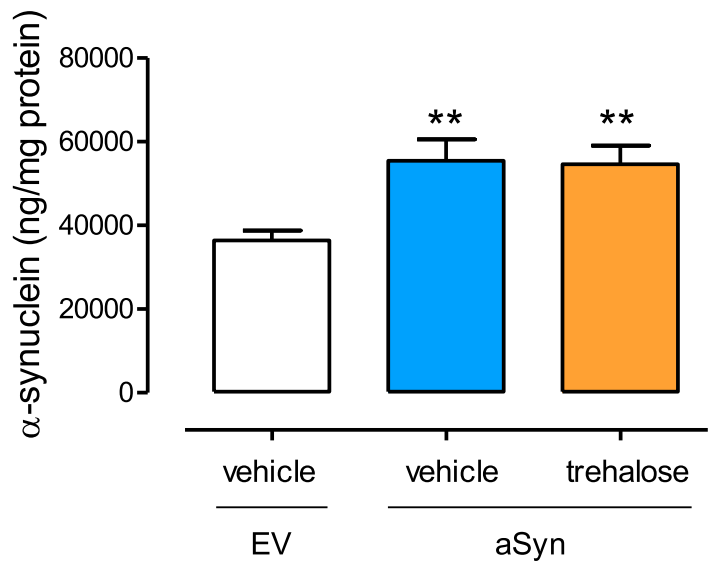

B

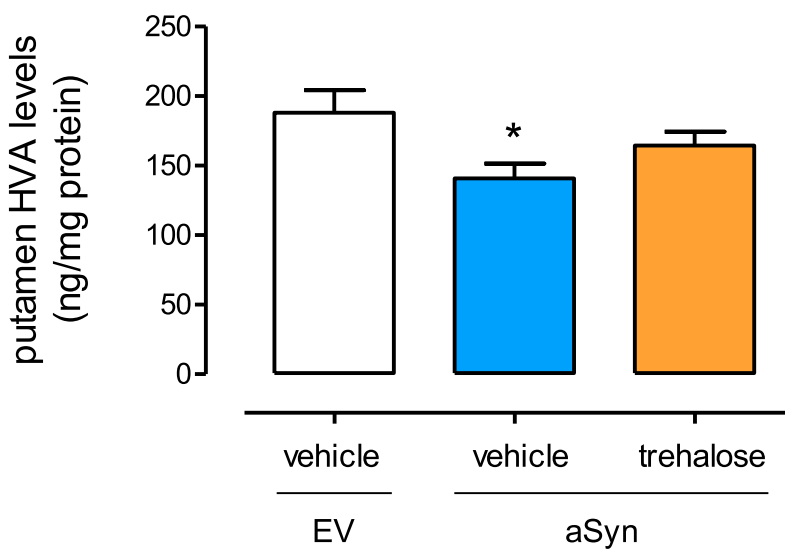

D

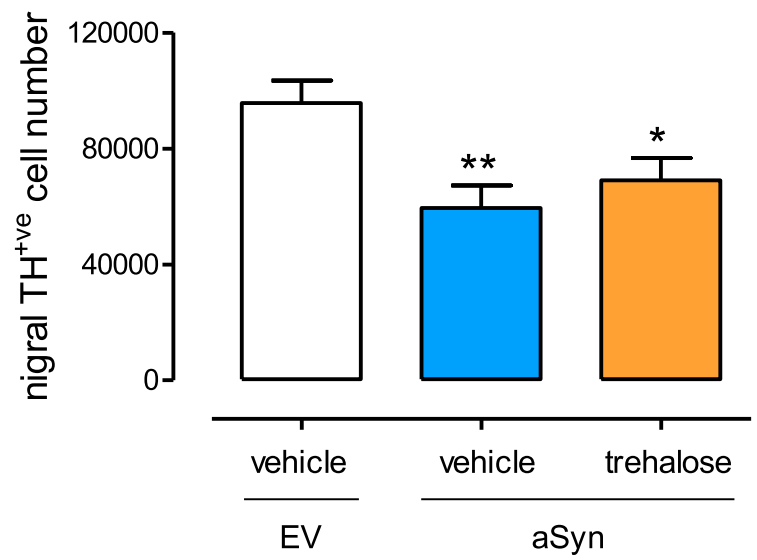

Fig. 4. Effect of repeated oral administration of trehalose in the AAV1/2-hourA53T-aSyn macaque. Trehalose $(2.67 \mathrm{~g} / \mathrm{kg}$ per day) was given as a single administration $(2.67 \mathrm{~g} / \mathrm{kg}$, daily by mouth) for 20 weeks. Trehalose significantly reduced AAV1/2-hourA53T-aSyn-induced loss of putamenal dopamine (A) and dopamine transporter (C). Trehalose also normalized putamenal HVA (B) to a level not significantly different from rats receiving AAV1/2-EV. Trehalose did not reduce nigral $\mathrm{TH}^{+\mathrm{ve}}$ cell loss (D) or alter aSyn expression in the putamen (E). Data are mean \pm S.E.M., $N=8$ to 9 macaques/group. ${ }^{*} P<0.05 ; * * P<0.01$; ${ }^{* * *} P<0.001$ vs. AAV1/2-EV, ${ }^{*} P<0.05$ vs. AAV1/2-A53T-aSyn. One-way ANOVA followed by Fisher's least-significant difference post hoc test.

impairment as measured by forelimb asymmetry (He et al., 2016). In this model, administration of trehalose for 6 weeks increased LC3-II, a marker of autophagy, and decreased striatal levels of aSyn and insoluble aSyn aggregates in the SN. Trehalose also reduced AAV1/2-hourA53T-aSyn-induced deficits in striatal dopamine and $\mathrm{TH}^{+\mathrm{ve}}$ cell number in the $\mathrm{SN}$ (He et al., 2016). Therefore, there is a substantial body of evidence demonstrating the potential of trehalose as a treatment of PD. However, there is no clear development path for how to translate preclinical findings, in which trehalose is administered in drinking water and trehalose exposure levels are not measured, into a product that could be taken forward into clinical trials in people with PD.

The current study represents the first report of how to address these issues. Our data show that in an AAV1/2-hourA53T-aSyn rat model of PD the same daily dose of trehalose $(2.67 \mathrm{~g} / \mathrm{kg}$ 
per day) is more efficacious in preventing the development of striatal dopamine loss and behavioral deficits when administered as a single oral dose compared with administering trehalose ad libitum in drinking water or as three daily administrations 8 hours apart. Terminal plasma and brain trehalose levels demonstrate that trehalose was only detectable in brains of mice that received trehalose as a single daily dose and provide a rationale as to why the single daily dose provided greater efficacy. Furthermore, we have defined the pharmacokinetic parameters of trehalose associated with efficacy in rodents and demonstrated that we can achieve comparable exposure in macaques. In macaques, we demonstrated that doubling the dose of trehalose led to a greater than 2-fold increase in both the values of $C_{\max }$ (3.4-fold increase) and $\mathrm{AUC}_{0-24}$ hours $(3.0$-fold increase). This suggests that large, single doses of trehalose increase the proportion of trehalose that enters systemic circulation compared with lower doses of trehalose, which explains why, in the rodent model of PD, the single, daily oral administration of trehalose was more efficacious than the same dose of trehalose administered in drinking water or as three daily doses 8 hours apart. Although it is not known why increasing the dose of trehalose increases the proportion of trehalose entering systemic circulation, we hypothesize that the enzyme responsible for converting trehalase to glucose, which is located primarily in the duodenum (Asp et al., 1975; Murray et al., 2000), becomes saturated when large doses of trehalose are administered, allowing a greater proportion of trehalose to enter systemic circulation without being metabolized.

In the unilateral AAV1/2-hourA53T-aSyn rat model, in vehicle-treated animals striatal dopamine levels were reduced by $66 \%$ compared with empty vector administered controls. The dopamine loss was associated with profound behavioral asymmetry, expressed as underuse of the forelimb contralateral to the hA53T-aSyn overexpression in the cylinder test. Dopamine levels were 54\% higher in AAV1/2-hourA53T-aSyn rats treated with trehalose $(2.67 \mathrm{~g} / \mathrm{kg}$ per day) administered once for 42 days. This magnitude of increase has functional benefit, being associated with a complete absence of behavioral deficit in the cylinder test and no increase in striatal dopamine turnover, a change considered to be compensating for reduced dopaminergic transmission. In the macaque model of PD that was recently developed (Koprich et al., 2016), AAV1/2-hourA53T-aSyn vectors were injected bilaterally into the SN. Over 4-8 months, this model showed an increase in striatal hA53T-aSyn, a decrease in $\mathrm{TH}^{+ \text {ve }}$ cells in the SN (by $\sim 40 \%$ ), and decreases in striatal dopamine and DAT (by $\sim 50 \%$ ). This model does not alter overall motor activity of the macaques; however, this is not surprising since people with PD do not exhibit motor symptoms until striatal dopamine loss is 60\% (Cheng et al., 2010). Moreover, in MPTP-lesioned macaques, parkinsonian symptoms are manifested when striatal dopamine and DAT loss is $>80 \%$ (Bezard et al., 2001). Thus, we use NHPs as a model of the early stages of PD when the pathology observed in NHPs is similar to that present in patients at diagnosis.

This study is the first time that this model has been used in a drug-development paradigm and the first time that trehalose has been evaluated, for any disease, in NHPs. We found that hA53T-aSyn-induced deficits to the dopaminergic system can be partly prevented by pharmacological interventions, which thus demonstrates the utility of this model as an aSyn-driven
NHP model of synucleinopathy in PD. The magnitude of changes in striatal dopamine and DAT produced by once daily administration of $2.67 \mathrm{~g} / \mathrm{kg}$ trehalose in the AAV1/2-hourA53T-aSyn macaque, were increases of $39 \%$ and $50 \%$, respectively, similar to the rat model (54\% increase in dopamine). These findings demonstrate that the beneficial effects of trehalose can translate from rodents to macaques when trehalose exposure levels are matched.

In the current studies, the beneficial effects of trehalose appeared restricted to the dopaminergic terminals, with trehalose reducing aSyn-induced loss of dopamine and DAT, but not reducing aSyn-induced loss of $\mathrm{TH}^{+ \text {ve }}$ cells in the $\mathrm{SN}$. Furthermore, trehalose did not alter levels of striatal aSyn. These results are in contrast to previous studies, which demonstrated that trehalose can protect $\mathrm{TH}^{+ \text {ve }}$ cells in the $\mathrm{SN}$ (Sarkar et al., 2014; Ferguson et al., 2015; He et al., 2016) and reduce striatal aSyn (He et al., 2016). Some of these observed differences are likely due to differences in the animal model used, e.g., AAV1/2-hourA53T-aSyn versus MPTP mouse. However, one of the studies (He et al., 2016) also used a rat AAV1/2-hourA53T-aSyn. It is unknown why trehalose provided more robust efficacy in the earlier study compared with our study, and additional studies to investigate the robustness of the trehalose response in this model of PD may be warranted.

The previous discussion of the effects of trehalose on $\mathrm{TH}$ neurons and aSyn levels notwithstanding, we have demonstrated that trehalose can prevent aSyn-induced loss of striatal dopaminergic function the in AAV1/2-hourA53TaSyn rat and macaque models of $\mathrm{PD}$, and these striatal effects appear robust across species, models, and research groups. Our data thus add support to the hypothesis that trehalose will also produce beneficial effects on striatal dopaminergic function in people with $\mathrm{PD}$, provided the correct plasma and brain exposures can be achieved. Our studies demonstrate that, in rats, the effect of trehalose on striatal dopamine can produce significant behavioral restoration and that complete normalization of striatal dopamine levels is not required for the normalization of behavior, indicating that there is a threshold level of dopamine above which normal behavior is restored. This may also be the case in $\mathrm{PD}$, where there is a 60\%-80\% loss in striatal dopamine at the time of diagnosis (Cheng et al., 2010). Presumably, prior to diagnosis, people with PD have reduced dopamine levels without exhibiting the classic symptoms of Parkinson's disease. The magnitude of effects observed in our studies while less than those reported in previous studies, may still be clinically relevant. For instance, in newly diagnosed subjects, trehalose could raise dopamine levels such that they return to being asymptomatic. Also, L-deprenyl (a monoamine-B inhibitor used in the treatment of PD) increased striatal dopamine levels by 40\%-50\% in subjects also receiving long-term treatment with L-DOPA and benzerazide (Riederer and Youdim, 1986), demonstrating that modest changes in striatal dopamine levels can be therapeutically beneficial.

In conclusion, we have demonstrated that single, daily oral administration of trehalose is more efficacious than administration of the same daily amount of trehalose either in drinking water or as three doses 8 hours apart. We have also shown that trehalose prevents synuclein-induced striatal dopaminergic deficits in rats and macaques and defined the pharmacokinetics of trehalose associated with this efficacy. 
This information will aid in the design of clinical trials ultimately aimed at evaluating trehalose as a treatment of PD.

\section{Authorship Contributions}

Participated in research design: Howson, Koprich, Ravenscroft, Johnston, Hill, Brotchie.

Conducted experiments: Howson, Koprich, Ravenscroft, Johnston, $\mathrm{Su}$.

Performed data analysis: Howson, Koprich, Ravenscroft, Johnston.

Wrote or contributed to the writing of the manuscript: Howson, Koprich, Ravenscroft, Johnston, Hill, Brotchie.

\section{References}

Asp NG, Gudmand-Höyer E, Andersen B, Berg NO, and Dahlqvist A (1975) Distribution of disaccharidases, alkaline phosphatase, and some intracellular enzymes along the human small intestine. Scand J Gastroenterol 10:647-651.

Bezard E, Dovero S, Prunier C, Ravenscroft P, Chalon S, Guilloteau D, Crossman AR, Bioulac B, Brotchie JM, and Gross CE (2001) Relationship between the appearance of symptoms and the level of nigrostriatal degeneration in a progressive 1-methyl4-phenyl-1,2,3,6-tetrahydropyridine-lesioned macaque model of Parkinson's disease. J Neurosci 21:6853-6861.

Casarejos MJ, Solano RM, Gómez A, Perucho J, de Yébenes JG, and Mena MA (2011) The accumulation of neurotoxic proteins, induced by proteasome inhibition, is reverted by trehalose, an enhancer of autophagy, in human neuroblastoma cells. Neurochem Int 58:512-520.

Cheng HC, Ulane CM, and Burke RE (2010) Clinical progression in Parkinson disease and the neurobiology of axons. Ann Neurol 67:715-725.

Chiba-Falek O, Lopez GJ, and Nussbaum RL (2006) Levels of alpha-synuclein mRNA in sporadic Parkinson disease patients. Mov Disord 21:1703-1708.

Cole NB, Murphy DD, Lebowitz J, Di Noto L, Levine RL, and Nussbaum RL (2005) Metal-catalyzed oxidation of $\alpha$-synuclein: helping to define the relationship between oligomers, protofibrils, and filaments. J Biol Chem 280 9678-9690.

Crowe JH (2007) Trehalose as a "chemical chaperone": fact and fantasy. Adv Exp Med Biol 594:143-158.

Dawson TM and Dawson VL (2003) Molecular pathways of neurodegeneration in Parkinson's disease. Science 302:819-822.

Dimasi P, Quintiero A, Shelkovnikova TA, and Buchman VL (2017) Modulation of p-eIF2 $\alpha$ cellular levels and stress granule assembly/disassembly by trehalose. Sci Rep 7:44088.

Echigo R, Shimohata N, Karatsu K, Yano F, Kayasuga-Kariya Y, Fujisawa A, Ohto T, Kita Y, Nakamura M, Suzuki S, et al. (2012) Trehalose treatment suppresses inflammation, oxidative stress, and vasospasm induced by experimental subarachnoid hemorrhage. J Transl Med 10:80.

Ferguson SA, Law CD, and Sarkar S (2015) Chronic MPTP treatment produces hyperactivity in male mice which is not alleviated by concurrent trehalose treatment Behav Brain Res 292:68-78.

Gao Z, Wang H, Zhang B, Wu X, Zhang Y, Ge P, Chi G, and Liang J (2018) Trehalose inhibits $\mathrm{H}_{2} \mathrm{O}_{2}$-induced autophagic death in dopaminergic SH-SY5Y cells via mitigation of ROS-dependent endoplasmic reticulum stress and AMPK activation. Int $J$ Med Sci 15:1014-1024.

He Q, Koprich JB, Wang Y, Yu WB, Xiao BG, Brotchie JM, and Wang J (2016) Treatment with trehalose prevents behavioral and neurochemical deficits produced in an AAV $\alpha$-synuclein rat model of Parkinson's disease. Mol Neurobiol 53: $2258-2268$

Hosseinpour-Moghaddam K, Caraglia M, and Sahebkar A (2018) Autophagy induction by trehalose: molecular mechanisms and therapeutic impacts. $J$ Cell Physiol 233:6524-6543.

Iwatsubo T (2003) Aggregation of $\alpha$-synuclein in the pathogenesis of Parkinson's disease. J Neurol 250 (Suppl 3):iii11-iii14.

Koprich JB, Johnston TH, Huot P, Reyes MG, Espinosa M, and Brotchie JM (2011) Progressive neurodegeneration or endogenous compensation in an animal model of Parkinson's disease produced by decreasing doses of alpha-synuclein. PLoS One 6 e17698.

Koprich JB, Johnston TH, Reyes G, Omana V, and Brotchie JM (2016) Towards a non-human primate model of alpha-synucleinopathy for development of therapeutics for Parkinson's disease: optimization of AAV1/2 delivery parameters to drive sustained expression of alpha synuclein and dopaminergic degeneration in macaque. PLoS One 11:e0167235.

Koprich JB, Johnston TH, Reyes MG, Sun X, and Brotchie JM (2010) Expression of human A53T alpha-synuclein in the rat substantia nigra using a novel AAV1/2 vector produces a rapidly evolving pathology with protein aggregation, dystrophic neurite architecture and nigrostriatal degeneration with potential to model the pathology of Parkinson's disease. Mol Neurodegener 5:43.
Krüger R, Kuhn W, Müller T, Woitalla D, Graeber M, Kösel S, Przuntek H, Epplen JT, Schöls L, and Riess O (1998) Ala30Pro mutation in the gene encoding $\alpha$-synuclein in Parkinson's disease. Nat Genet 18:106-108.

Lan DM, Liu FT, Zhao J, Chen Y, Wu JJ, Ding ZT, Yue ZY, Ren HM, Jiang YP, and Wang J (2012) Effect of trehalose on PC12 cells overexpressing wild-type or A53T mutant $\alpha$-synuclein. Neurochem Res 37:2025-2032.

Mirzaie M, Karimi M, Fallah H, Khaksari M, and Nazari-Robati M (2018) Downregulation of matrix metalloproteinases 2 and 9 is involved in the protective effect of trehalose on spinal cord injury. Int J Mol Cell Med 7:8-16.

Mizunoe Y, Kobayashi M, Sudo Y, Watanabe S, Yasukawa H, Natori D, Hoshino A, Negishi A, Okita N, Komatsu M, et al. (2018) Trehalose protects against oxidative stress by regulating the Keap1-Nrf2 and autophagy pathways. Redox Biol 15: $115-124$

Murray IA, Coupland K, Smith JA, Ansell ID, and Long RG (2000) Intestinal trehalase activity in a UK population: establishing a normal range and the effect of disease. Br J Nutr 83:241-245.

Pagliassotti MJ, Estrada AL, Hudson WM, Wei Y, Wang D, Seals DR, Zigler ML, and LaRocca TJ (2017) Trehalose supplementation reduces hepatic endoplasmic reticulum stress and inflammatory signaling in old mice. J Nutr Biochem 45:15-23.

Perucho J, Gómez A, Muñoz MP, de Yébenes JG, Mena MA, and Casarejos MJ (2016) Trehalose rescues glial cell dysfunction in striatal cultures from HD R6/1 mice at early postnatal development. Mol Cell Neurosci 74:128-145.

Polymeropoulos MH, Lavedan C, Leroy E, Ide SE, Dehejia A, Dutra A, Pike B, Root $\mathrm{H}$, Rubenstein J, Boyer R, et al. (1997) Mutation in the $\alpha$-synuclein gene identified in families with Parkinson's disease. Science 276:2045-2047.

Portbury SD, Hare DJ, Finkelstein DI, and Adlard PA (2017a) Trehalose improves traumatic brain injury-induced cognitive impairment. PLoS One 12:e183683.

Portbury SD, Hare DJ, Sgambelloni C, Perronnes K, Portbury AJ, Finkelstein DI, and Adlard PA (2017b) Trehalose improves cognition in the transgenic Tg2576 mouse model of Alzheimer's disease. J Alzheimers Dis 60:549-560.

Riederer P and Youdim MB (1986) Monoamine oxidase activity and monoamine metabolism in brains of Parkinsonian patients treated with l-deprenyl. $J$ Neurochem 46:1359-1365.

Sarkar S, Chigurupati S, Raymick J, Mann D, Bowyer JF, Schmitt T, Beger RD, Hanig JP, Schmued LC, and Paule MG (2014) Neuroprotective effect of the chemical chaperone, trehalose in a chronic MPTP-induced Parkinson's disease mouse model. Neurotoxicology 44:250-262.

Sarkar S, Davies JE, Huang Z, Tunnacliffe A, and Rubinsztein DC (2007) Trehalose, a novel mTOR-independent autophagy enhancer, accelerates the clearance of mutant huntingtin and alpha-synuclein. J Biol Chem 282:5641-5652.

Siderowf A and Stern M (2003) Update on Parkinson disease. Ann Intern Med 138 $651-658$

Singleton AB, Farrer M, Johnson J, Singleton A, Hague S, Kachergus J, Hulihan M, Peuralinna T, Dutra A, Nussbaum R, et al. (2003) $\alpha$-Synuclein locus triplication causes Parkinson's disease. Science 302:841.

Song W, Patel A, Qureshi HY, Han D, Schipper HM, and Paudel HK (2009) The Parkinson disease-associated A30P mutation stabilizes $\alpha$-synuclein against proteasomal degradation triggered by heme oxygenase-1 over-expression in human neuroblastoma cells. J Neurochem 110:719-733.

Spina-Purrello V, Giliberto S, Barresi V, Nicoletti VG, Giuffrida Stella AM, and Rizzarelli E (2010) Modulation of PARP-1 and PARP-2 expression by L-carnosine and trehalose after LPS and INF $\gamma$-induced oxidative stress. Neurochem Res 35:2144-2153.

Tanji K, Miki Y, Maruyama A, Mimura J, Matsumiya T, Mori F, Imaizumi T, Itoh K, and Wakabayashi K (2015) Trehalose intake induces chaperone molecules along with autophagy in a mouse model of Lewy body disease. Biochem Biophys Res Commun 465:746-752.

West MJ, Slomianka L, and Gundersen HJ (1991) Unbiased stereological estimation of the total number of neurons in the subdivisions of the rat hippocampus using the optical fractionator. Anat Rec 31:482-497.

Whishaw IQ and Kolb B (2005) The Behaviour of the Laboratory Rat: A Handbook with Tests, Oxford University Press, New York.

Wu F, Xu HD, Guan JJ, Hou YS, Gu JH, Zhen XC, and Qin ZH (2015) Rotenone impairs autophagic flux and lysosomal functions in Parkinson's disease. Neuroscience 284:900-911.

Yoon YS, Cho ED, Ahn WJ, Lee KW, Lee SJ, and Lee HJ (2017) Is trehalose an autophagic inducer? Unraveling the roles of non-reducing disaccharides on autophagic flux and alpha-synuclein aggregation. Cell Death Dis 8:e3091.

Zarranz JJ, Alegre J, Gómez-Esteban JC, Lezcano E, Ros R, Ampuero I, Vidal L, Hoenicka J, Rodriguez O, Atarés B, et al. (2004) The new mutation, E46K, of $\alpha$-synuclein causes Parkinson and Lewy body dementia. Ann Neurol 55:164-173.

Zhao J, Zhi X, Pan L, and Zhou P (2017) Trehalose inhibits A53T mutant $\alpha$-synuclein overexpression and neurotoxicity in transduced PC12 cells. Molecules 22:1293.

Address correspondence to: Patrick A. Howson, Junaxo Inc., Krembil Discovery Tower, 60 Leonard Ave, Toronto, Ontario, M5T 0S8, Canada. E-mail: p.howson@junaxo.com 